\title{
Impact of Different Antibiotic Regimens on Patients with Respiratory Tract Infection
}

\author{
Liu Chen ${ }^{1}$, Weijun Jin ${ }^{1, ~}$, Rong Jian ${ }^{2}$ \\ ${ }^{1}$ Department of Medicine, The First Affiliated Hospital of Jinan University, Guangzhou, China \\ ${ }^{2}$ Department of Pharmacy, Huizhou Third People's Hospital, Huizhou City, China \\ Email address: \\ 597963395@qq.com (Liu Chen), jinwj66@sina.com (Weijun Jin), 584626610@qq.com (Rong Jian) \\ ${ }^{*}$ Corresponding author
}

To cite this article:

Liu Chen, Weijun Jin, Rong Jian. Impact of Different Antibiotic Regimens on Patients with Respiratory Tract Infection. Pharmaceutical Science and Technology. Vol. 5, No. 1, 2021, pp. 37-39. doi: 10.11648/j.pst.20210501.15

Received: June 1, 2021; Accepted: June 8, 2021; Published: June 16, 2021

\begin{abstract}
To assess impact of different antibiotic regimens on patients with respiratory tract infection, we establish a randomized controlled trial for comparison of different antibiotic regimens. From May 2019 to February 2021, we collected valid data from 182 patients in the hospital. This study consisted of 3 steps. First, we invited the patients with respiratory tract infection who meet the inclusion criteria. Also, patients were divided into control group $(n=98)$ and intervention group ( $n=84)$ according to the antibiotic regimen they received. Second, we collected the data by questionnaires, including basic patient characteristics, treatment period, treatment cost, and treatment effect. Third, we analyze the data by software. In this study, the less days of treatment period and less payment of treatment in intervention group patient than control group patients, that their results between were significantly different. Also, treatment effect of two antibiotic regimens were similar, that the rates of treatment effective were no significantly different. In summary, we found that the patients who received levofloxacin lactate sodium chloride injection treatment had shorter treatment period and less treatment cost than the patients who received ceftazidime treatment, but their treatment effects were similar.
\end{abstract}

Keywords: Antibiotic Regimen, Respiratory Tract Infection, Treatment Period, Treatment Cost

\section{Introduction}

Lower respiratory infections (LRI) are a major public health problem in patients of all ages. Globally, the reports indicated that hospitals received more than 420 million of patients with lower respiratory infections $[1,2]$. Although antibiotics can provide effective treatment to patients with lower respiratory infections, there are still 1.4 million deaths a year among patients $[3,4]$. Doctor often use antibiotics to treat patients with lower respiratory infections. To prevent infections, antibiotic prophylaxis is commonly used in these patients, either as a standalone measure or as an adjunct to immunoglobulin replacement therapy $[1,5,6]$. However, different antibiotic regimens provided different treatment effect and treatment cost in similar patients with lower respiratory infections [7-9]. Those are reasons why exploring Impact of different antibiotic regimens on patients with respiratory tract infection.
The patients with lower respiratory infections consisted of milder phenotypes and recurrent infections [10]. milder phenotypes patients are generally treated with antibiotic prophylaxis alone. Also, recurrent infections patients are generally treated with replacement immunoglobulin [11-13]. The use of antibiotic prophylaxis in the recurrent infection population varies significantly [14]. Therefore, assessing impact of different antibiotic regimens on patients with respiratory tract infection is worth studying. The aim of this study was to assess impact of different antibiotic regimens on patients with respiratory tract infection.

\section{Methods}

\subsection{Participants Enrollment and Survey Methods}

From May 2019 to February 2021, we collected the data from 200 patients who were diagnosed as respiratory tract infection. But 18 patients were excluded as they lack 
necessary information during study, so we only collected valid data from 182 patient in the hospital. This study consisted of 3 steps. First, we invited the patients with respiratory tract infection who meet the inclusion criteria. Also, patients were divided into control group $(n=98)$ and intervention group $(\mathrm{n}=84)$ according to the antibiotic regimen they received. Second, we collected the data by questionnaires, including basic patient characteristics, treatment period, treatment cost, and treatment effect. Third, we analyze the data by software.

Control group patients received cephalosporin antibiotics and ceftazidime for injection during treatment. According to the patient's condition, the doctor took 1 2 $\mathrm{g}$ of the injection, dissolved in $100 \mathrm{~mL} 0.9 \%$ sodium chloride solution, and took the mixed solvent to drip the patient, twice a day, until the patient's symptoms improved significantly.

In intervention group, patients received floxacin antibiotics and levofloxacin lactate sodium chloride injection during treatment. According to the patient's condition, $0.5 \sim 1 \mathrm{~g}$ of the injection was dissolved in $100 \mathrm{~mL}$ of $0.9 \%$ sodium chloride solution, and the mixed solvent was taken to drip the patient, twice a day.

\subsection{Statistical Analysis}

Excel and SPSS22.0 were used to establish a database and analyzed the valid data. In addition, we described the results by mean and standard deviation (SD). Statistical significance was observed at level of 0.05 .

\section{Result}

To explore impact of different antibiotic regimens on patients with respiratory tract infection, we established a randomized controlled trial for comparison of different antibiotic regimens. In patient characteristics, the patients were no significantly different between intervention group and control group, including gender, age, and type of respiratory tract infection $(p>0.05)$, as shown in Table 1 . This result ruled out as patient characteristics on the results of deviation.

Table 1. Basic patient characteristics.

\begin{tabular}{|c|c|c|c|c|c|}
\hline Item & $\begin{array}{l}\text { Gender (female) } \\
(n, \%)\end{array}$ & $\begin{array}{l}\text { Age (year) } \\
(\text { mean } \pm \text { SD) }\end{array}$ & Bronchitis [n (\%)] & $\begin{array}{l}\text { Chronic bronchitis } \\
{[\mathrm{n}(\%)]}\end{array}$ & Pneumonia [n (\%)] \\
\hline Intervention group $(n=84)$ & $44(52.4 \%)$ & $40.51 \pm 7.44$ & $22(26.2 \%)$ & $25(29.8 \%)$ & $27(32.1 \%)$ \\
\hline Control group $(\mathrm{n}=98)$ & $56(57.1 \%)$ & $41.25 \pm 7.12$ & $28(28.6 \%)$ & $31(36.9 \%)$ & $39(46.4 \%)$ \\
\hline$t / X^{2}$ & 4.161 & 3.562 & 1.445 & 1.194 & 1.081 \\
\hline$P$ value & $>0.05$ & $>0.05$ & $>0.05$ & $>0.05$ & $>0.05$ \\
\hline
\end{tabular}

The Table 2 shown that the comparison of treatment period and treatment cost between two groups. Compared with control group, intervention group patients had shorter treatment period and less treatment cost in study $(5.35 \pm 1.08 \mathrm{vs}$
$7.26 \pm 1.52 \quad \& \quad 272.67 \pm 26.77$ vs $449.57 \pm 30.95)$. The comparison between intervention group and control were significantly different $(\mathrm{p}=0.0142 \& \mathrm{p}=0.004)$.

Table 2. Comparison of treatment period and treatment cost (mean $\pm S D)$.

\begin{tabular}{lll}
\hline Item & treatment period (day) & treatment cost (RMB) \\
\hline Intervention group $(\mathrm{n}=84)$ & $5.35 \pm 1.08$ & $272.67 \pm 26.77$ \\
Control group $(\mathrm{n}=98)$ & $7.26 \pm 1.52$ & $449.57 \pm 30.95$ \\
$\mathrm{t}$ & 6.118 & 24.955 \\
P value & 0.0142 & 0.004 \\
\hline
\end{tabular}

In the result of treatment, two antibiotic regimen groups had similar results, that they were no significantly different in outcome of treatment result. Most treatment results were significant effect of treatment in patients with respiratory tract infection. Although control group had lower rate of treatment effective compare with intervention group, their results were no significantly different in this study (Table 3 ).

Table 3. Comparison of treatment effect [n (\%)].

\begin{tabular}{|c|c|c|c|c|}
\hline Item & Effective treatment & Significant effect of treatment & Ineffective treatment & Total rate of treatment effective \\
\hline Intervention group $(n=84)$ & 30 & 49 & 5 & $79(94.0 \%)$ \\
\hline Control group $(\mathrm{n}=98)$ & 25 & 61 & 12 & $86(87.8 \%)$ \\
\hline $\mathrm{X}^{2}$ & & & & 0.784 \\
\hline$P$ value & & & & 0.681 \\
\hline
\end{tabular}

\section{Discussion}

In this study, we demonstrated that the antibiotic regimen of intervention group can improve treatment period and treatment cost for patients with respiratory tract infection. To clarify impact of different antibiotic regimens on patients with respiratory tract infection, we established a randomized controlled trial and analyzed comparison of different antibiotic regimens. The result shown that intervention group patients had shorter treatment period and less treatment cost in their treatment, but their treatment effects were similar.

As shown in Table 2, we found that the less days of treatment period and less payment of treatment in intervention 
group patient than control group patients. The possible reasons were that ceftazidime for injection has a good bactericidal effect on escherichia coli, Bacillus pneumoniae and other bacteria, and has a good bacteriostatic effect on nitrate negative bacilli and Alkali-producing bacilli, which can realize the effective relief and treatment of symptoms of patients with lower respiratory tract infection. Levofloxacin lactate sodium chloride injection has a wide antibacterial spectrum, and its antibacterial effect is relatively strong, and has good bactericidal and bacteriostatic effects on most of the bacteria of lower respiratory tract infection. As shown in Table 3 , treatment effect of two antibiotic regimens were similar, that the rates of treatment effective were no significantly different. This result demonstrated that the two antibiotic regimens had similar treatment effect.

Several studies in related fields clearly demonstrated that levofloxacin lactate sodium chloride injection has good bactericidal and bacteriostatic effects on most of the bacteria of lower respiratory tract infection [15, 16]. Likewise, levofloxacin lactate sodium chloride injection provided shorter treatment period and less treatment cost compare with ceftazidime.

In limitation, our subject were patients with respiratory tract infection, so it is not known whether our results are application to the patient with other diseases. Also, we examined only 182 patients, the result of this study may have been due to chance. The results must be confirmed in a large study.

\section{Conclusion}

In conclusion, the patients who received levofloxacin lactate sodium chloride injection treatment had shorter treatment period and less treatment cost than the patients who received ceftazidime treatment, but their treatment effects were similar.

\section{References}

[1] Bonilla Francisco A, Isil Barlan, Helen Chapel, Costa-Carvalho Beatriz T, Charlotte Cunningham-Rundles, Teresa de la Morena M, et al. International consensus document (ICON): Common variable immunodeficiency disorders. J Allergy ClinImmunol Pract 2016; 4 (1): 38-59.

[2] Marciano Beatriz E, Holland Steven M. Primary immunodeficiency diseases: current and emerging therapeutics. Front Immunol 2017; 8: 937.

[3] Bell BG, Schellevis F, Stobberingh E, Goossens H, Pringle M. A systematic re- view and meta-analysis of the effects of antibiotic consumption on antibiotic resistance. BMC Infect Dis 2014; 14: 13 .

[4] Cassini A, Högberg LD, Plachouras D, Quattrocchi A, Hoxha
A, Simonsen GS, et al. Attributable deaths and disability-adjusted life-years caused by infections with antibiotic-resistant bacteria in the EU and the European Economic Area in 2015: a population-level modelling analysis. Lancet Infect Dis 2019; 19: 56-66.

[5] Gulliford MC, Dregan A, Moore MV, Ashworth M, Staa T van, McCann G, et al. Continued high rates of antibiotic prescribing to adults with respiratory tract infection: survey of 568 UK general practices. BMJ Open 2014; 4: e006245.

[6] Bonilla Francisco A, Khan David A, Ballas Zuhair K, Javier Chinen, Frank Michael M, Hsu Joyce T, et al. Practice parameter for the diagnosis and management of primary immunodeficiency. J Allergy Clin Immunol 2015; 136 (5): $1178-8$.

[7] Youngmee Jee, Johan Carlson, Eric Rafai, Kunda Musonda, Giang Huong Tran Thi, Paula Daza, et al. Antimicrobial resistance: a threat to global health. Lancet Infect Dis 2018; 18 (9): 939-40.

[8] Jain S, Williams DJ, Arnold SR, Ampofo K, Bramley AM, Reed $\mathrm{C}$, et al. Community-acquired pneumonia requiring hospitalization among U.S. children. N Engl J Med 2015; 372 (9): 835-45.

[9] Hagedoorn NN, Borensztajn DM, Nijman R, Balode A, von BothU, Carrol ED, et al. Variation in antibiotic prescription rates in febrile children presenting to emergency departments across Europe (MOFICHE): A multicentre observational study. PLoS Med 2020; 17: 1-23.

[10] Pouwels KB, Dolk FCK, Smith DRM, Robotham JV, Smieszek T. Actual versus 'ideal' antibiotic prescribing for common conditions in English primary care. J Antimicrob Chemother. 2018; 73: ii19-26.

[11] Dekker ARJ, Verheij TJM, Velden AWvan der. Inappropriate antibiotic prescription for respiratory tract indications: most prominent in adult patients. Fam Pract. 2015; 32 cmv019.

[12] McKay R, Mah A, Law MR, McGrail K, Patrick DM. Systematic review of factors associated with antibiotic prescribing for respiratory tract infections. Antimi-crob Agents Chemother. 2016; 60: 4106-18.

[13] Lassi ZS, Das JK, Haider SW, Salam RA, Qazi SA, Bhutta ZA. Systematic review on antibiotic therapy for pneumonia in children between 2 and 59 months of age. Arch Dis Childhood 2014; 99 (7): 687-93.

[14] Carol Kelly, Chalmers James D, Iain Crossingham, Nicola Relph, Felix Lambert M, Evans David J, et al. Macrolide antibiotics for bronchiectasis. Cochrane Database Syst Rev $2018 ; 3$ (3).

[15] Li X, Guo Y, Hao SG, et al. Clinical analysis of montelukast combined with extended nursing in children with bronchial asthma. Journal of Hainan Medical University. 2017; 23 (1): 139-141.

[16] Yang XZ. Analysis on the effect of health education implementation in the nursing of patients with bronchial asthma. Systems Medicine. 2017; 2 (16): 126-128. 